\title{
Attentional biases in depression: \\ Relation to disorder severity, rumination, and anhedonia
}

Audrey Krings ${ }^{1}$, Alexandre Heeren ${ }^{2,3}$, Philippe Fontaine ${ }^{4}, \&$ Sylvie Blairy ${ }^{1}$

${ }^{1}$ Psychology and Neurosciences of Cognition, Liège Université, Liège, Belgium.

Place des Orateurs, 1, 4000 Liège, Belgium.

Email: audrey.krings@uliege.be ; Sylvie.blairy@uliege.be

${ }^{2}$ Psychological Science Research Institute, Université catholique de Louvain, Louvain-la-

Neuve, Belgium.

Place Cardinal Mercier 10, 1348, Louvain-la-Neuve, Belgium.

${ }^{3}$ Institute of Neuroscience, Université catholique de Louvain, Brussels, Belgium

Avenue Mounier 53, 1200, Woluwe-Saint-Lambert, Belgium.

Email: alexandre.heeren@uclouvain.be

${ }^{4}$ Psychiatry service, CHU de Charleroi, Belgium.

Rue de l'Hôpital, 55, 6030 Marchienne-au-Pont, Belgium.

Email: philippe.fontaine@chu-charleroi.be

Corresponding author

Audrey Krings, PhD student

Liège Université

Trifacultaire (B33), Place des Orateurs 1

4000 Liège

(Belgium)

Psychology and Neurosciences of Cognition Research Unit - PsyNCog

Email: audrey.krings@uliege.be

Phone: + 3243662337

Declarations of interest: None.

Note. This Manuscript is a preprint that has not yet been accepted for formal publication in a peer-reviewed journal. 


\section{Abstract}

Introduction: According to cognitive models of depression, selective attentional biases (ABs) for mood-congruent information are core vulnerability factors of depression maintenance. However, findings concerning the presence of these biases in depression are mixed. This study aims to clarify the presence of these $\mathrm{ABs}$ among individuals with clinical and subclinical depression.

Method: We compared three groups based on a semi-structured diagnostic interview and a depressive symptoms scale (BDI-II): 34 individuals with major depressive disorder (clinically depressed); 35 with a dysphoric mood but without the criteria of major depressive disorder (i.e., subclinically depressed), and 26 never been depressed individuals. We examined AB for sad and happy materials in three modified versions of the exogenous cueing task using scenes, facial expressions, and words. Brooding, anhedonia, and anxiety were also evaluated.

Results: In contrast to our hypotheses, there were no ABs for negative or positive information, regardless of the task and the groups. Neither the association between AB toward negative information and brooding nor the one between $\mathrm{AB}$ away from positive stimuli and anhedonia was significant. Bayes factors analyses revealed that the present pattern of findings does not result from a lack of statistical power.

Discussion: Our results raise questions about how common $\mathrm{AB}$ is in depression. From a theoretical point of view, because individuals with depression did not exhibit $A B$, our results also seemingly challenge the claim that $\mathrm{AB}$ figures prominently in the maintenance of depression. We believe the present null results to be particularly useful for future meta-research in the field.

Keywords: depression, rumination, attentional biases, cognitive models of depression 


\section{Introduction}

Major depressive disorder (MDD) is one of the most prevalent mental disorders, as well as one of the leading causes of disability worldwide. It results in substantial social costs (e.g., social withdrawal), personal suffering (e.g., marital issues), and economic costs related to health care or absence from work [1]. Furthermore, the rates of relapse and recurrence of depression remain high [2]. In this way, there is a need to improve our understanding of the processes involved in the emergence, maintenance, and recurrence of depression. Recent advances in clinical psychology have suggested that several dysfunctional psychological processes may be involved in depression $[3,4]$. These psychological processes may be behavioral, cognitive, metacognitive, emotional/affective, motivational, or interpersonal. The present study aims to clarify the characteristics of attentional biases in depression.

According to prominent cognitive models of depression, selective attentional biases to mood-congruent information are key vulnerability factors that contribute to maintaining the disorder $[5,6]$. The concept of attentional bias (AB) toward mood-congruent stimuli refers to a differential allocation of attentional resources toward emotional stimuli (e.g., sad faces) compared to neutral stimuli (e.g., neutral faces) [7]. Attentional operations of information treatment have different components [8]. The first is an initial shift of attention toward a stimulus; the second is an attentional engagement with this stimulus; the third is a disengagement of attention from this stimulus. Two distinct ABs have been observed in depression. The first one stresses prolonged attention to mood-congruent information found at a later stage of information processing (e.g., $1000 \mathrm{~ms}$ ) and characterized by a difficulty disengaging attention from this information $[9,10]$. The second one features reduced attention toward positive information in depressed individuals compared to controls, which is sometimes called an anhedonic bias. In fact, it is an absence of the protective bias usually observed in healthy subjects. Although preliminary data suggest a slower engagement with 
positive stimuli in depressed participants compared to non-depressed participants [11], the very nature of the attentional components involved in anhedonic bias remains poorly understood.

It should be noted that findings concerning the presence of $\mathrm{ABs}$ in depression are mixed. Indeed, the two types of AB (i.e., difficulty disengaging attention from moodcongruent information and reduced maintenance of attention to positive information) have been observed in clinically and subclinically depressed individuals but not in non-depressed individuals $[11,12]$. On the other hand, a few studies failed to report these ABs in people with MDD or dysphoria compared to non-depressed individuals $[13,14]$. To help us to move forward regarding these different results, we examined previously published studies relying on an exogenous cueing task with long SOA $(>750 \mathrm{~ms})$ conducted among individuals with depression (see Table 1) $)^{1}$. Evidence of AB for sadness was reported in three studies [15-17], whereas evidence for $\mathrm{AB}$ toward positive stimuli was described in two studies [17] and not investigated in one [15]. The sample characteristics (e.g., clinical status) or the methodological choices (e.g., stimulus onset asynchrony, material) do not seem to explain these inconsistencies provided that these studies (regardless of their results) were characterized by different clinical status, stimulus onset asynchrony, or materials. As such, uncertainty remains regarding the presence of $\mathrm{AB}$ in depression. In addition, prior studies often comprised samples of undergraduate students, and only a few studies included adults (e.g. [14]). The main goals were twofold. First, we aimed at testing the replicability of previous studies reporting an $\mathrm{AB}$ among adults with depression. Second, we also wanted to further clarify the nature of the attentional components (see below) at play.

\footnotetext{
${ }^{1}$ We used the following keywords to identify the studies: attention, bias, attention bias, cognitive bias, depression, dysphoria, negative information, exogenous cueing task, spatial cueing task, and modified Posner. We searched in the following databases: PsycInfo, PubMed, and Scopus.
} 
In this project, we thus assessed ABs among both currently depressed (clinically diagnosed MDD) and subclinically depressed individuals, as compared to never-depressed individuals. We hypothesized that, at a later stage of information processing, both clinically and subclinically depressed individuals would maintain their attention on sad stimuli with longer times to disengage from these stimuli. They would also avoid positive stimuli. Provided that the attentional component involved in this type of $\mathrm{AB}$ is not well understood, we have no specific hypothesis regarding the attentional components involved. Conversely, never-depressed individuals would avoid sad stimuli with shorter times to disengage from sad stimuli and focus their attention on positive stimuli.

Rumination is another vulnerability factor in depression. Brooding rumination, which is "a passive comparison of one's current situation with some unachieved standard" [18], is particularly maladaptive and is strongly linked to depression [19]. According to Koster et al. [20], impaired disengagement from negative information may lead to persistent brooding, which maintains a depressive mood. Prior research has pointed to selective attention to negative stimuli as a potential harbinger of brooding [18,19], and some have distinguished between the engagement versus disengagement components of $\mathrm{AB}$ to test the impaired disengagement hypothesis. Those studies reported a significant association between brooding scores and scores for disengagement from sad information but no association with engagement scores [22-24]. Eye-tracking studies also support these findings with similar results in a non-depressed sample, a subclinical sample, and a clinical sample with MDD [2527]. From these data, we expected to find a significant positive correlation between disengagement scores for sad stimuli and scores for brooding in the overall sample.

Anhedonia, defined as diminished pleasure and/or decreased reactivity to pleasurable stimuli $[28,29]$, is characterized by a hypo-sensitive response to reward [30] and precedes the onset of depression in non-clinical populations [31]. In their meta-analysis of selective 
attention in depression, Armstrong and Olatunji [32] assumed that the hypo-sensitive response to reward might influence the stimulus driven-system responsible for selective attention. From their view, positive and rewarding stimuli may fail to capture depressed participants' attention or may reduce their motivation to maintain the attentional focus on positive stimuli. However, uncertainties remain regarding the relations between selective attention to positive stimuli and hyposensitivity to reward or loss of pleasure [5,33]. To our knowledge, only Brailean et al. [30] have explored the relationship between anhedonia and selective attention to positive stimuli. Specifically, they investigated the link between the reduced sensitivity to reward and the development of $\mathrm{AB}$ toward conditioned rewarding stimuli in dysphoria. Their results suggest that dysphoric individuals failed to develop a reward-related $\mathrm{AB}$, unlike nondepressed individuals. The authors concluded that the impaired processing of rewarding stimuli might be a vulnerability factor for anhedonia in depression. Accordingly, we hypothesized that anhedonia might affect the attentional processing of positive information. In other words, we expected to find a significant negative correlation between $\mathrm{AB}$ for positive stimuli and anhedonia scores in our overall sample without specific hypotheses regarding attentional engagement or disengagement components.

Verbal stimuli (i.e., words) are the most frequently used material in studies exploring the interaction between $\mathrm{AB}$ and mental rumination as well as in studies using exogenous cueing tasks. Nonetheless, one might expect that nonverbal stimuli, such as faces or pictures, would attract the attention of depressed individuals more quickly than verbal ones because of their higher interpersonal relevance. These stimuli appear more ecologically valid than words in investigating $\mathrm{AB}$ [34]. The meta-analysis by Peckham et al. [35] suggests that ABs tasks with verbal and nonverbal stimuli may yield similar effect sizes. However, a more recent meta-analysis recommends using photographs rather than words to study the $\mathrm{AB}$ toward positive information [36]. Given the uncertainty concerning the material, we employed both 
verbal (words) and nonverbal material (scenes and faces) and made no specific predictions regarding the effect of material on $\mathrm{AB}$.

Anxiety might also play a role in the ABs reported in depression. A previous study showed that participants with high anxiety symptoms, in addition to high depressive symptoms, paid more attention to sad stimuli and less attention to positive stimuli, whereas participants with high levels of depression without anxiety did not [37]. Consequently, we measured anxiety to control for its potential impact on AB.

---INSERT Table 1 HERE ---

\section{Method}

\subsection{Participants}

The participants were French-speaking adults aged between 18 and 55 years. They were recruited from the community and mental health care centers via advertisements, university intranets, and the waiting rooms of health care centers. We recruited participants via a two-step procedure. First, they were all initially screened using the Beck Depression Inventory-IIII (BDI-II) to assess depression symptoms [38]. Then, based on their BDI-II score, they were invited to take part in the experiment, wherein we asked them to complete the BDI-II a second time to control for their mood on the day of the experiment. Participants with no history of psychiatric disorders and with a BDI-II score of less than 8 at both the first and second sessions were classified as never-depressed. Participants who fulfilled the criteria for MDD based on the DSM-IV criteria and had a minimum score of 12 at both evaluation sessions were regarded as clinically depressed. Participants who had a minimum score of 12 at the first evaluation and 10 at the second but who did not fulfill the MDD criteria were regarded as subclinically depressed. The cut-offs applied were based on those provided by Beck et al. [38] and other studies made in this field.

Data analyses were based on 95 adults (62 females, 33 males) with a mean age of 38.01 years $(S D=11.12$; range: $18-55)$. Exclusion criteria were a history of psychotic mental 
disorders, history of bipolar disorder, history of substance abuse or dependence (less than three years of abstinence - except nicotine or caffeine), a history of any neurological disorder, anxiolytic/drug consumption on the day of the evaluation, recent changes in antidepressant medication (less than four weeks) and vision that was not normal or corrected to normal. Figure 1 depicts the participants' flow throughout the enrollment.

$$
\text { ---INSERT Figure } 1 \text { HERE --- }
$$

\subsection{A priori power analysis}

The required sample size was a priori determined to reach a predicted power of .80 $($ alpha $=.05$, beta $=.20)$ for a two-way interaction with a small effect size, $f=.15$ [39], with one within-subject factor and one between-subject factor. We anticipated this effect size from a previous meta-analysis [35].

\subsection{Materials}

Materials consisted of a semi-structural interview, three computerized tasks, and selfreport questionnaires. ${ }^{2}$

\subsubsection{Current mental disorders}

The Mini-International Neuropsychiatric Interview (MINI) is a semi-structured interview focusing on current and lifetime psychiatric disorders based on DSM-IV criteria [40]. The interview was conducted by the first author, who is a certified clinical psychologist, and by two advanced clinical psychology students under the supervision of the first author ${ }^{3}$.

\subsubsection{Depressive symptomatology}

The BDI-II is a 21-item scale that assesses the severity of depressive symptoms during the last two weeks [38]. Higher scores indicate higher severity. We used the validated Frenchspeaking version of the scale [41]. In the present sample, the Cronbach's $\alpha$ was .93 .

\footnotetext{
${ }^{2}$ In addition to the measures reported in this article, the participants completed three self-report scales. Relations between these scales and $\mathrm{AB}$ are reported elsewhere.

${ }^{3}$ The two students were intensively trained to administer the MINI. Their training included sessions of role-play (at least two 2h-sessions) and several practices under supervision before the start of the experiment.
} 


\subsubsection{Anxiety}

Spielberger's State and Trait Anxiety Inventory (STAI Form Y-B) comprises two 20item scales assessing state and trait anxiety [42]. Higher scores indicate higher anxiety. We used the validated French-speaking version of these scales [43]. In this study, Cronbach's $\alpha$ was .95 for the state scale and .94 for the trait scale.

\subsubsection{Mental rumination}

The Ruminative Response Scale (RRS) is a 22-item scale assessing rumination when respondents feel depressed, sad, or discouraged [18]. Higher sum scores indicate greater tendencies to engage in rumination. Two subscales are identified, one related to brooding (5 items) and one related to reflection (5 items). The latter was not reported because this aspect of rumination is more adaptive than brooding and less central in depression. Higher scores on these subscales indicate a higher brooding component and a higher reflective component, respectively. We used the validated French-speaking version of the scale [44]. In this sample, Cronbach's $\alpha$ for the brooding subscale was .81 .

\subsubsection{Anhedonia}

The Temporal Experience of Pleasure Scale (TEPS) is an 18-item scale assessing trait dispositions in anticipatory and consummatory experiences of pleasure [45]. Two subscales are identified, one related to anticipatory pleasure (10 items) and one about consummatory pleasure (10 items). Higher scores indicate greater anticipation of pleasure and greater consummatory pleasure, respectively. We used the validated French-speaking version of the scale [46]. In this sample, Cronbach's $\alpha$ was .78 for the anticipatory pleasure subscale and .71 for the consummatory pleasure subscale. 


\subsubsection{Demographic questionnaire}

A sociodemographic questionnaire addressed questions about age, sex, marital status, employment status, medication, quality of vision, neurological history, and past depressive episodes.

\subsubsection{Exogenous cueing task (ECT)}

The ECT is a reaction-time-based attention task, which was programmed using EPrime software and run on a computer with a $60 \mathrm{~Hz}, 15$-inch color monitor. The original exogenous cueing task asked participants to detect a visual target presented in the left or right peripheral location of a screen [47]. In emotion research, this paradigm has been modified by using emotional and neutral cues to allow a comparison of their attentional processing. Here, three tasks were created with different materials (15 scenes, 15 faces, and 15 words). Scenes were selected from the International Affective Picture System (IAPS) [48] and faces from the Karolinska Directed Emotional Face database (KDEF) [49,50]; the words were common nouns. Cues were selected based on their emotional content and were matched for valence and arousal for each stimulus of each task. Words were also matched for their length. ${ }^{4}$

Scenes were 133 pixels high X 100 pixels wide and were located on the left and right sides of a fixation cross with visual angles of $2.43^{\circ} \mathrm{X} 0.86^{\circ}$. Faces were 100 pixels high $\mathrm{X}$ 136 pixels wide with visual angles of $2.05^{\circ} \mathrm{X} 1.25^{\circ}$. Words appeared in 10-point Courier New with visual angles of $1.97^{\circ}$. Each trial started with a fixation cross for $1000 \mathrm{~ms}$ in the center of the screen. Then, the emotional cue appeared on the left or right side of the screen for $1000 \mathrm{~ms}$ (SOA of $1000 \mathrm{~ms}$ ). Finally, the target (E" or "F") remained onscreen until a response occurred. If a participant did not respond within 3 seconds, the next trial started. A black background intertrial was then presented for $1650 \mathrm{~ms}$ before the upcoming trial started.

\footnotetext{
${ }^{4}$ One hundred and eighty stimuli were selected by the first author based on validation studies and other studies of $\mathrm{AB}$ in depression. Sixty scenes, 60 faces, and 60 words were rated by a population of psychology students for the intensity of valence, arousal, and emotion, as well as familiarity in the case of words.
} 
Figure 2 illustrates this sequence. In the test trials, two-thirds of all trials (120 trials) were valid (left cue-left target and right cue-right target), one-sixth (30 trials) were invalid (left cue-right target and right cue-left target), and one-sixth (30 trials) had no cues. Our decision to rely on this trial distribution arises from prior research using a similar task [51,52]. We presented the stimuli in random order in the left or right hemifield with an equal number of presentations for each stimulus (five times) and each emotion category (sad, happy, and neutral) (30 trials each).

The Split-half reliability indices were computed separately for each task via Spearman-Brown correlations with the first and the second half of trials of each experimental condition. Spearman-Brown correlations ranged from 0.77 (Scenes, Happy invalid) to 0.96 (Scenes, Happy valid). We run the same analyses for $\mathrm{CV}$, engagement, and disengagement scores. Spearman-Brown correlations ranged from -0.06 (Scenes, engagement for sad cues) and 0.36 (Faces, CV for happy cues). All these statistical analyses are reported in the supplementary material section (i.e., Tables S1 and S2). Following recommendations in research transparency and replicability, the E-Prime versions of the tasks as well as all the stimuli can are available via the following link: https://osf.io/k97tf/?view_only=bf803c5e485b4dfc8b4d8a3ca0f79c26.

---INSERT Figure 2 HERE ---

\subsection{Procedure}

Each participant was tested alone in a quiet room with dim light. Participants first completed the clinical interview and then the self-report questionnaires and all three spatial cueing tasks. The order of the questionnaires remained fixed, whereas the order of the three spatial cueing tasks was counterbalanced across participants. To complete the three spatial cueing tasks, participants were seated $60 \mathrm{~cm}$ from the computer. They were asked to discriminate, as quickly as possible, the nature of the target, the letter "E" or "F" (target "E": left mouse button with left index finger; target " $F$ ": right mouse button with right index 
finger), without sacrificing accuracy. The instructions were presented onscreen. Participants were instructed that a cue would precede the onset of the target and that the cue predicted the location of the target on some but not all trials. Participants practiced the attentional task for 10 trials. The test phase consisted of one block with 180 trials. Trials were presented in a different order for each participant.

This study was approved by the local Ethical Committee ${ }^{5}$. All participants gave their informed consent. The total time for data acquisition was approximately two hours (i.e., preparation of the subject, familiarization with the tasks, breaks, debriefing).

\subsection{Data analysis}

First, a cue validity (CV) index was calculated for each emotion (sad, happy, and neutral) by subtracting the mean reaction times (RTs) for valid trials from the mean RTs for invalid trials. With a short stimulus onset asynchrony (SOA), participants typically respond faster to valid than invalid trials. This phenomenon is called the cue validity effect. However, at longer SOAs, the cue validity effect often disappears or even reverses. This phenomenon is called the inhibition of return effect (IOR) [53]. IOR may suggest that attention to the location of a previously attended stimulus is inhibited in favor of a new spatial location $[53,54]$. With longer SOAs, as were used in this study, IOR is usually observed. However, when an emotionally charged cue is used, some participants may continue to respond faster to valid trials and present a cue validity effect because the emotional cue captures their attention. At longer SOAs, a cue validity effect suggests that attention is maintained on the cue. The CV index must be calculated for each valence to allow comparisons.

For each task, CV scores were entered in a 3 (Valence: sad, happy, neutral) X 3 (Group: clinically depressed, subclinically depressed, never-depressed) mixed-design analysis of variance (ANOVA). Estimates of effect sizes are also reported (i.e., partial eta-squared;

\footnotetext{
${ }^{5}$ The central ethical committee of Liège University located in CHU Sart-Tilman, B35, 4000 Liège approved this study in 2018 (Belgium number: B707201734155, reference number: 2017-278).
} 
$\eta p 2)$. To control for the potential impact of anxiety on $A B$, two additional analyses of covariance (ANCOVA) were conducted with state and trait anxiety scores as covariates.

For each task, an attentional engagement score (i.e., by subtracting the mean RTs of valid emotional trials from the mean RTs of valid neutral trials) and an attentional disengagement score (i.e., by subtracting the mean RTs of invalid neutral trials from the mean RTs of invalid emotional trials) were calculated for positive and sad stimuli to allow group comparisons [17].

\section{Results}

\subsection{Group characteristics}

Group characteristics appear in Table 2. There were no significant group differences in terms of age, $(F(2,92)=1.65, p=.20, \eta p 2=.03)$, gender $\left(\right.$ Pearson $\left.\chi^{2}=0.97 ; d f=2 ; p=.62\right)$, and ethnicity (all participants were Caucasian). Depression, brooding, state anxiety, and trait anxiety scores were significantly different in the three groups, with moderate to large effect sizes. Anticipatory and consummatory pleasure scores were significantly different in group comparisons, with moderate to large effect sizes, except for the comparison between the subclinically depressed group and the never-depressed group, whose effect sizes were small. Table 3 reports the means and standard deviations of all scales. $T$-tests are reported in the supplementary material section (i.e., Table S3).

\section{---INSERT Table 2 HERE --- \\ ---INSERT Table 3 HERE ---}

\subsection{Data preparation}

First, we discarded trials with errors from the analyses $(0.58 \%$ of all data). To take into account the processing speed of each participant, we followed Radcliff's (1993) guidelines in dealing with outliers [55]. To do so, we relied on an individual approach based on deviations below or above each participant's mean for each experimental condition. 
Participants' RTs more than 1.96 standard deviations from their individual mean RT for all indices (Invalid Sad, Valid Sad, Invalid Happy, Valid Happy, Invalid Neutral, and Valid Neutral) were considered as outliers ${ }^{6}$. These outliers were excluded on the basis that they indicate anticipatory responses $(0.21 \%$ of all data) or delayed responses $(3.55 \%$ of all data). In the three tasks, the three groups did not differ with regard to the number of erroneous responses $(F(4,184)=.40, p=.81, \eta p 2=.00)$, anticipatory responses $(F(4,184)=1.69, p=$ $.15,, \eta \mathrm{p} 2=.04)$ and delayed responses $(F(4,184)=.16, p=.96, \eta \mathrm{p} 2=.00)$. None of the participants exhibited more than $15 \%$ of erroneous responses or outliers. The analyses were conducted on the remaining $95.67 \%$ of the data. The de-identified data, as well as the MATLAB script of the cleaning procedure reported above, can be downloaded on the Open Science Framework (https://osf.io/k97tf/?view_only=bf803c5e485b4dfc8b4d8a3ca0f79c26).

\subsection{Overall effects}

Mean RTs and standard deviations for all tasks are shown in Table 4. The results of the 3 X 3 ANOVA on CV scores were non-significant for all three tasks. No other effects were significant (all $p \mathrm{~s}>.05) . F$-tests, $p$-values, and effect sizes $\left(\eta_{\mathrm{p}}{ }^{2}\right)$ as a function of material and mixed-design ANOVA $\left(\eta_{\mathrm{p}}^{2}\right)$ are reported in Table 5.

To control for the effect of fatigue, the mean RTs for the first 20 trials and the last 20 trials were computed for every participant in all three tasks. These mean RTs were entered in a 3 (Type of stimuli: faces, words) X 2 (Time: first trials, last trials) X 3 (Group: clinically depressed, subclinically depressed, never-depressed) mixed-design ANOVA. No main or interaction effects were significant (all $\left.F_{\mathrm{S}}>.25\right)$.

Three (Valence: sad, happy, and neutral) X 2 (Cue validity: valid, invalid) X 3 (Group: clinically depressed, subclinically depressed, control) ANOVAs were also performed on mean

\footnotetext{
${ }^{6}$ All analyses were also conducted with stricter outliers' criteria-i.e., RT below $200 \mathrm{~ms}$ and above $1000 \mathrm{~ms}$ were considered as outliers as in Koster et al. (2006). Nine participants had more than 10\% of errors or delayed answers and were excluded from the analyses. These different outliers' criteria did not change results and conclusions.
} 
RTs to evaluate the attentional cueing effect. The results revealed a significant main effect of validity in the scene task $\left(F(1,92)=8.33, p=.004, \eta_{\mathrm{p}}{ }^{2}=.08\right)$, the face task $(F(1,92)=13.35$, $\left.p=.000, \eta_{\mathrm{p}}^{2}=.13\right)$ and the word task $\left(F(1,92)=9.11, p=.003, \eta_{\mathrm{p}}{ }^{2}=.09\right)$, with slower RTs for invalid cued locations than for valid ones. These results suggest an attentional cueing effect, as expected.

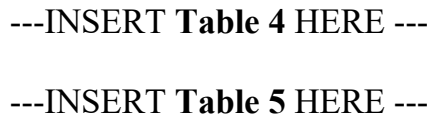

\subsection{Independent sample t-tests}

The $t$-tests were first performed on CV scores, even where the results of ANOVAs were not significant to report the effect sizes of the hypothesized differences. The $t$-tests were performed between groups for sad and happy valences (see Table 6) and between valences for each group (see Table 7). Bonferroni adjusted $t$-tests indicated that none of the comparisons were statistically significant.

$$
\begin{aligned}
& \text {---INSERT Table } 6 \text { HERE --- } \\
& \text {---INSERT Table } 7 \text { HERE --- }
\end{aligned}
$$

The $t$-tests were then performed on engagement and disengagement scores to report the effect sizes of the differences. The $t$-tests were performed between groups on engagement and disengagement scores for sad and happy valence and between engagement and disengagement scores for sad and happy valence in each group. Bonferroni adjusted $t$-tests indicated that none of the comparisons were statistically significant (these results are reported in supplementary material Tables S4, S5, and S6). Finally, given the poor split-half reliability of CV scores, engagement, and disengagement scores, $t$-tests were also performed between groups for invalid and valid mean reaction times as well as between valences for each group. Bonferroni adjusted $t$-tests indicated that none of the comparisons were statistically significant (these results are reported in supplementary material Tables S7 and S8). 


\subsection{Correlation analyses}

Contrary to our hypotheses, correlation analysis revealed no significant correlations between CV scores for sad stimuli and depression severity and between CV scores for happy stimuli and depression severity scores in all three materials (all $r \mathrm{~s}<.13$, with all $p \mathrm{~s}>.17$ ). No significant relationship between $\mathrm{CV}$ scores for sad stimuli and brooding was reported (all $r \mathrm{~s}<$ 1.00 , with all $p \mathrm{~s}>.10)$. In addition, correlation analyses revealed that the correlations between disengagement scores for sad stimuli and brooding were small and not significant (all $r \mathrm{~s}<.11$, with all $p \mathrm{~s}>.30)$. No significant associations between $\mathrm{CV}$ scores for happy stimuli and anticipatory and consummatory pleasure scores were reported with any of the three materials (all $r \mathrm{~s}<.02$, with all $p \mathrm{~s}>.15$ ). Moreover, the correlations between engagement and disengagement scores for happy stimuli and anhedonia were small and not significant (all $r \mathrm{~s}<$ .19 , with all $p \mathrm{~s}>.07)$. To control for the potential influence of symptom severity, we also computed partial correlations controlling for BDI-II scores. These partial correlations were not significant.

As expected, anxiety and depression scores were significantly correlated $(r=.80, p<$ $.001)$, as were brooding and depression $(r=.63, p<.001)$, anticipation of pleasure and depression $(r=-.56, p<.001)$, and consummatory pleasure and depression $(r=-.49, p<.001)$.

\subsection{Complementary analyses}

Although our sample size had enough power to detect medium-to-large effect sizes, one cannot exclude the possibility that some analyses would require a larger sample size. However, neither the p-values nor the effect sizes associated with our non-significant effects even approached statistical significance. Moreover, it should be noted that a complementary $a$ priori power analysis for the main ANOVA suggested that a total sample size of at least 357 participants would be required to produce enough power to detect a small-size effect (i.e., $d=$ $.15)$ in the present study. However, such small effect sizes have no clinical relevance. To further 
examine this issue, we thus calculated Bayes factors (BF01) using default priors in JASP [56] to express the likelihood of the null $(\mathrm{H} 0)$ over the alternative hypothesis $(\mathrm{H} 1)$ given the data for each analysis of our study. A BF under 3 is conventionally considered to indicate 'anecdotal' evidence, while a BF under 10 indicates 'moderate' evidence. Analyses systematically revealed BF01 under 3 (statistical results are reported in supplementary material Tables S9, S10, S11, and S12). Altogether, all these analyses suggest that the pattern of findings cannot be attributed solely to a lack of power.

\section{Discussion}

In this study, we investigated whether attentional engagement and disengagement toward sad and happy stimuli, as assessed using verbal and nonverbal emotional cues, vary according to depression severity. We also aimed to replicate previous results showing a significant relationship between attentional disengagement from sad information and brooding

rumination, and finally, explore the relationship between attentional bias to positive information and anhedonia. In both groups of individuals with depression, we did not observe the maintenance of attention on sad stimuli or withdraw attention from happy stimuli at a later stage of information processing.

Moreover, in both groups of individuals with depression, there was no significant difficulty disengaging attention from sad stimuli. Finally, there were no significant relationships between attentional disengagement from sad stimuli and brooding rumination, or between $\mathrm{AB}$, attentional engagement or disengagement with positive information and anhedonia. Altogether, these results are at odds with the notion that individuals with depression are characterized by AB toward sad or away from happy stimuli, and thus cast some doubts about the robustness of earlier findings $[57,58]$.

To explain the absence of $\mathrm{AB}$, we compared this study to previously published studies relying on an exogenous cueing task with long SOA ( $>750 \mathrm{~ms})$ that were conducted among 
individuals with depression. The results, effect sizes, and methodological characteristics of the five studies are reported in Table 1 [14-17].

Some differences in the design are apparent. Contrary to four of the five other studies, our ECT was a discrimination task and a task with predictive cues. Likewise, we did not use fixation cues, as other studies did, before the presentation of the cue. In an ECT, these methodological choices might not potentiate the appearance of an IOR [59]. Thus, these choices might explain why an IOR effect for neutral information does not characterize the neverdepressed group in our study, as is usually observed in studies with long SOA. A small IOR in the never-depressed group reduces the likelihood of finding significant differences between groups. On the other hand, these limitations do not explain the lack of an enhanced cue validity effect for emotional valence in our sample. Future studies should further clarify this issue.

SOAs used in ECT studies described in Table 1 vary from $750 \mathrm{~ms}$ to $1500 \mathrm{~ms}$. In Ellenbogen et al. (2009), an SOA of $750 \mathrm{~ms}$ was associated with difficulty in disengaging from mood-congruent information. Koster et al. (2005) and Baert et al. (2010) used an SOA of 1500 ms and also found maintained attention for negative words in depressed groups. However, in Elgersma et al., (2018), an SOA of $1250 \mathrm{~ms}$ was not related to any AB. In the present study, we decided to choose an SOA of $1000 \mathrm{~ms}$, which is a duration located between $750 \mathrm{~ms}$ and 1500 ms. One cannot exclude that other results would have emerged with a presentation duration inferior or superior to $1000 \mathrm{~ms}$. As such, although the current presentation duration should not come as a surprise given these previous studies, future studies should further clarify this issue.

The selection criteria employed in this study did not differ from those reported in Table 1: cut-off scores for the BDI-II were used to designate participants as dysphoric or not, and a semi-structured interview served to investigate past or present psychiatric disorders. Moreover, it is worth noting that our clinically depressed groups showed the expected characteristics of depression in terms of severity of depressive symptoms, anxiety, brooding, and anhedonia. 
Indeed, the individuals of the clinically depressed group were characterized by higher levels of depression, anxiety, and brooding than the subclinically depressed group, which, in turn, exhibited higher levels than the never-depressed group [18]. The clinically depressed group was also characterized by lower levels of anticipatory and consummatory pleasure than the neverdepressed group, which dovetails earlier studies [26]. Finally, our results corroborate previous data suggesting a strong relationship between depression and anhedonia [56]. Therefore, the non-significant results cannot be attributed to a lack of differences between groups in terms of symptom severity and disturbed processes, especially since the effect sizes for these differences were moderate-to-large.

Rather than a methodological problem, the absence of evidence for $\mathrm{AB}$ in our sample may mirror the heterogeneity of depression. Indeed, depression is characterized by highly heterogeneous depressive symptoms and a wide diversity of profiles $[58,59]$. In our sample, we compared our participants' expression of symptoms by recoding each symptom from the BDIII as absent (item $=0$ ) or present (item $\geq 1)$. All participants in the subclinically depressed group had a different profile from the other participants, and only two participants in the clinically depressed group had a similar profile when all symptoms were reported, which suggests that symptom profiles in our sample were heterogeneous. ABs might be related to specific depressive symptoms or part of a network of related symptoms [60,61]. Future research may benefit from exploring the interplay between $\mathrm{AB}$ with specific depressive symptoms like increased interest and involvement in everyday activities using computational network analysis $[60,61]$.

\subsection{Limitations}

This study has limitations. First, although we instructed participants to fixate their attention to a predetermined spatial location during the presentation of stimuli, we could not ensure that participants did so. Recently developed experimental eye-tracking paradigms 
enabling verification of participants' initial attentional allocation and subsequent attentional shift may accomplish this aim (e.g., [62,63]).

Second, even if fatigue did not influence the mean processing speed of the last trials, it might have altered the fluctuation of performance during the tasks due to a decrease of vigilance and impact the present results.

Third, like most extant procedures for assessing $\mathrm{AB}$ (e.g., [64-66]), the psychometric properties of the task used in this study were less than ideal. In this way, our results echo recent doubts about the relevance of relying on difference scores in $\mathrm{AB}$ research $[65,67,68]$. When cognitive measures are expected to be strongly correlated between participant's performance for different conditions, a difference score is likely to increase the proportion of measurement error relative to between-participant variance and then reduce the reliability. In the ECT tasks, the cognitive measures (e.g., mean RT for invalid and valid trials) are highly correlated, leading to unreliable resultant CV, engagement, and disengagement scores [64].

Furthermore, the temporal experience of pleasure scale used in the present study only distinguishes between a couple of reward processes found to be relevant to depression (i.e., anticipation and consumption of reward; e.g. [69]). Future studies should thus investigate the relations between reward learning or motivation for reward and selective attention in depression. Finally, the total sample of participants with MDD was too small to reliably examine potential gender differences or test for the influence of antidepressant medication on AB. It is important to note that previous studies have not shown antidepressant to influence later stage of treatment information in subclinically or clinically depressed participants [70,71].

\section{Conclusion}

Results revealed no ABs for negative or positive information, regardless of the material and the symptom severity. In line with some past studies, these findings do not support the view that $\mathrm{AB}$ toward sad stimuli or away from happy one is a crucial feature of depression. Our 
findings cast some doubt on the robustness of earlier findings and contribute to magnifying the gap between research results and cognitive models of depression. In future research, there is a need to critically examine the active mechanisms and the symptoms underlying attentional biases and to propose more relevant cognitive models of depression. Finally, the impact of the emotional contexts (e.g., stressful, sad, anger, or happy situations) on the display of AB could also be further investigated.

\section{Declarations of interest}

None.

\section{Acknowledgments}

The authors thank Ezio Tirelli for his guidance regarding the results and discussion, Thomas Lambert for his valuable support with programming, and Dr. Yun-Marie Vandriette for her help in the recruitment.

\section{Funding sources}

This research did not receive any specific grant from funding agencies in the public, commercial, or not-for-profit sectors. 
References:

[1] Kessler RC, Bromet EJ. The Epidemiology of Depression Across Cultures. Annu Rev Public Health 2013;34:119-38. doi:10.1146/annurev-publhealth-031912-114409.

[2] Bockting CL, Hollon SD, Jarrett RB, Kuyken W, Dobson K. A lifetime approach to major depressive disorder: The contributions of psychological interventions in preventing relapse and recurrence. Clin Psychol Rev 2015;41:16-26. doi:10.1016/j.cpr.2015.02.003.

[3] Kinderman P, Tai S, Pontin E, Schwannauer M, Jarman I, Lisboa P. Causal and mediating factors for anxiety, depression and well-being. $\mathrm{Br} \mathrm{J}$ Psychiatry 2015;206:456-60. doi:10.1192/bjp.bp.114.147553.

[4] Lemoult J, Joormann J, Kircanski K, Gotlib IH. Attentional bias training in girls at risk for depression. J Child Psychol Psychiatry 2016;57:1326-33. doi:10.1111/jcpp.12587.

[5] Grahek I, Everaert J, Krebs RM, Koster EHW. Cognitive Control in Depression: Toward Clinical Models Informed by Cognitive Neuroscience. Clin Psychol Sci 2018;6:464-80. doi: $10.1177 / 2167702618758969$.

[6] Lemoult J, Gotlib IH. Depression : A cognitive perspective. Clin Psychol Rev 2019;69:51-66. doi:10.1016/j.cpr.2018.06.008.

[7] Bar-Haim Y, Lamy D, Pergamin L, Bakermans-Kranenburg MJ, van IJzendoorn MH. Threatrelated attentional bias in anxious and nonanxious individuals: a meta-analytic study. Psychol Bull 2007;133:1-24. doi:10.1037/0033-2909.133.1.1.

[8] Posner MI, Inhoff AW, Friedrich FJ, Cohen A. Isolating attentional systems: A cognitiveanatomical analysis. Psychobiology 1987;15:107-21. doi:10.3758/BF03333099.

[9] Sears CR, Thomas CL, LeHuquet JM, Johnson JCS. Attentional biases in dysphoria: An eyetracking study of the allocation and disengagement of attention. Cogn Emot 2010;24:1349-68. doi:10.1080/02699930903399319.

[10] Winer ES, Salem T. Reward Devaluation: Dot-Probe Meta-Analytic Evidence of Avoidance of Positive Information in Depressed Persons. Psychol Bull 2017;142:18-78. doi:10.1037/bul0000022.

[11] Sanchez A, Romero N, De Raedt R. Depression-related difficulties disengaging from negative faces are associated with sustained attention to negative feedback during social evaluation and predict stress recovery. PLoS One 2017:1-24. doi:10.1371/journal.pone.0175040.

[12] Lazarov A, Ben-Zion Z, Shamai D, Pine DS, Bar-Haim Y. Free viewing of sad and happy faces in depression: A potential target for attention bias modification. J Affect Disord 2018;238:94100. doi:10.1016/j.jad.2018.05.047.

[13] Koster EHW, Leyman L, De Raedt R, Crombez G. Cueing of visual attention by emotional facial expressions: The influence of individual differences in anxiety and depression. Pers Individ Dif 2006;41:329-39. doi:10.1016/j.paid.2005.12.022.

[14] Elgersma HJ, Koster EHW, Van Tuijl LA, Hoekzema A, Penninx BWJH, Bockting CLH, et al. Attentional bias for negative, positive, and threat words in current and remitted depression. PLoS One 2018;13:1-23. doi:10.1371/journal.pone.0205154.

[15] Ellenbogen MA, Schwartzman AE. Selective attention and avoidance on a pictorial cueing task during stress in clinically anxious and depressed participants. Behav Res Ther 2009;47:128-38. doi:10.1016/j.brat.2008.10.021.

[16] Baert S, De Raedt R, Koster E. Depression-related attentional bias: The influence of symptom severity and symptom specificity. Cogn Emot 2010;24:1044-52. doi:10.1080/02699930903043461. 
[17] Koster EHW, De Raedt R, Goeleven E, Franck E, Crombez G. Mood-Congruent Attentional Bias in Dysphoria: Maintained Attention to and Impaired Disengagement From Negative Information. Emotion 2005;5:446-55. doi:10.1037/1528-3542.5.4.446.

[18] Treynor W, Gonzalez R, Nolen-Hoeksema S. Rumination reconsidered: A psychometric analysis. Cognit Ther Res 2003;27:247-59. doi:10.1023/A:1023910315561.

[19] Watkins ER. Constructive and unconstructive repetitive thought. Psychol Bull 2008;134:163206. doi:10.1037/0033-2909.134.2.163.

[20] Koster EHW, De Lissnyder E, Derakshan N, De Raedt R. Understanding depressive rumination from a cognitive science perspective: The impaired disengagement hypothesis. Clin Psychol Rev 2011;31:138-45. doi:10.1016/j.cpr.2010.08.005.

[21] Donaldson C, Lam D, Mathews A. Rumination and attention in major depression. Behav Res Ther 2007;45:2664-78. doi:10.1016/j.brat.2007.07.002.

[22] Beckwé M, Deroost N. Attentional biases in ruminators and worriers. Psychol Res 2016;80:95262. doi:10.1007/s00426-015-0703-8.

[23] Grafton B, Southworth F, Watkins E, MacLeod C. Stuck in a sad place: Biased attentional disengagement in rumination. Emotion 2016;16:63-72. doi:10.1037/emo0000103.

[24] Southworth F, Grafton B, MacLeod C, Watkins E. Heightened ruminative disposition is associated with impaired attentional disengagement from negative relative to positive information: support for the "impaired disengagement" hypothesis. Cogn Emot 2017;31:42234. doi:10.1080/02699931.2015.1124843.

[25] Holas P, Krejtz I, Rusanowska M, Rohnka N, Nezlek JB. Attention to negative words predicts daily rumination among people with clinical depression: evidence from an eye tracking and daily diary study. Cogn Emot 2018:1-7. doi:10.1080/02699931.2018.1541168.

[26] Owens M, Gibb BE. Brooding rumination and attentional biases in currently non-depressed individuals : an eye- tracking study. Cogn Emot 2017;31:1062-9. doi:10.1080/02699931.2016.1187116.

[27] Yaroslavsky I, Allard ES, Sanchez-Lopez A. Can't look Away: Attention control deficits predict Rumination, depression symptoms and depressive affect in daily Life. J Affect Disord 2019;245:1061-9. doi:10.1016/j.jad.2018.11.036.

[28] Admon R, Pizzagalli DA. Dysfunctional Reward Processing in Depression. Curr Opin Psychol 2015;4:114-8. doi:10.1016/j.copsyc.2014.12.011.

[29] Rizvi SJ, Pizzagalli DA, Sproule BA, Kennedy SH. Assessing anhedonia in depression: Potentials and pitfalls. Neurosci Biobehav Rev 2016;65:21-35. doi:10.1016/j.neubiorev.2016.03.004.

[30] Zald DH, Treadway MT. Reward Processing, Neuroeconomics, and Psychopathology. Annu Rev Clin Psychol 2017:471-97. doi:10.1146/annurev-clinpsy-032816-044957.

[31] Bylsma LM, Morris BH, Rottenberg J. A meta-analysis of emotional reactivity in major depressive disorder. Clin Psychol Rev 2008;28:676-91. doi:10.1016/j.cpr.2007.10.001.

[32] Armstrong T, Olatunji BO. Eye tracking of attention in the affective disorders: A meta-analytic review and synthesis. Clin Psychol Rev 2012;32:704-23. doi:10.1016/j.cpr.2012.09.004.

[33] Brailean AM, Koster EHW, Hoorelbeke K, De Raedt R. Attentional modulation by reward and punishment cues in relation to depressive symptoms. J Behav Ther Exp Psychiatry 2014;45:3519. doi:10.1016/j.jbtep.2014.03.003.

[34] Gilboa-Schechtman E, Ben-Artzi E, Jeczemien P, Marom S, Hermesh H. Depression impairs the 
ability to ignore the emotional aspects of facial expressions: Evidence from the Garner task. Cogn Emot 2004;18:209-31. doi:10.1080/02699930341000176a.

[35] Peckham AD, McHugh RK, Otto MW. A meta-analysis of the magnitude of biased attention in depression. Depress Anxiety 2010;27:1135-42. doi:10.1002/da.20755.

[36] Pool E, Brosch T, Delplanque S, Sander D. Attentional Bias for Positive Emotional Stimuli : A Meta-Analytic Investigation. Psychol Bull 2016;142:79-106. doi:10.1037/bul0000026.

[37] Sass SM, Heller W, Fisher JE, Silton RL, Stewart JL, Crocker LD, et al. Electrophysiological evidence of the time course of attentional bias in non-patients reporting symptoms of depression with and without co-occurring anxiety. Front Psychol 2014;5:1-11. doi:10.3389/fpsyg.2014.00301.

[38] Beck AT, Steer RA, Brown G. Beck Depression Inventory Second Edition Manual. San Antonio: The Psychological Corporation; 1996.

[39] Cohen J. Statistical power analysis for the behavioral sciences (2nd ed.). Hillsdale, NJ: Lawrence Erlbaum; 1988.

[40] Lecrubier Y, Sheehan D, Weiller E, Amorim P, Bonora I, Sheehan K, et al. The Mini International Neuropsychiatric Interview (MINI). A short diagnostic structured interview: Reliability and validity according to the CIDI. Eur Psychiatry 1997;12:224-31. doi:10.1016/S0924-9338(97)83296-8.

[41] Centre de Psychologie appliquée. Manuel du BDI-II. Paris: Editions du centre de psychologie appliquée; 1996.

[42] Spielberger CD, Gorsuch RL, Lushene R, Vagg PR. Manual for the State-Trait Anxiety Inventory. Palo Alto, CA: 1983.

[43] Bruchon-Schweitzer M, Paulhan I. Adaptation française de l'Inventaire d'Anxiété Trait-Etat. In Forme Y(STAI Y). Paris: Editions du Centre de Psychologie Appliquée; 1993.

[44] Baeyens C., Douilliez C., Philippot P. Measure of the brooding and reflection dimension in the Ruminative Response Scale: a French validation n.d.

[45] Gard DE, Gard MG, Kring AM, John OP. Anticipatory and consummatory components of the experience of pleasure: A scale development study. J Res Pers 2006;40:1086-102. doi:10.1016/j.jrp.2005.11.001.

[46] Favrod J, Ernst F, Giuliani F, Bonsack C. Validation française de l'échelle d'expérience temporelle du plaisir. Encephale 2009. doi:10.1016/j.encep.2008.02.013.

[47] Posner MI. Orientation of attention. Q J Exp Psychol 1980;32:3-25.

[48] Lang, P.J., Bradley, M.M., \& Cuthbert BN. International affective picture system (IAPS): Affective ratings of pictures and instruction manual. Technical Report A-8. Tech Rep A-8 2008:Tech. Rep. A-8. doi:10.1016/j.epsr.2006.03.016.

[49] Lundqvist D, Flykt A, Öhman A. The Karolinska Directed Emotional Faces-KDEF. Stockholm: Department of Neurosciences Karolinska Hospital; 1998.

[50] Goeleven E, De Raedt R, Leyman L, Verschuere B. The Karolinska Directed Emotional Faces: A validation study. Cogn Emot 2008;22:1094-118. doi:10.1080/02699930701626582.

[51] Amir N, Elias J, Klumpp H, Przeworski A. Attentional bias to threat in social phobia: Facilitated processing of threat or difficulty disengaging attention from threat? Behav Res Ther 2003;41:1325-35. doi:10.1016/S0005-7967(03)00039-1.

[52] Heeren A, Peschard V, Philippot P. The causal role of attentional bias for threat cues in social 
anxiety: A test on a cyber-ostracism task. Cognit Ther Res 2012;36:512-21. doi:10.1007/s10608011-9394-7.

[53] Posner MI, Cohen Y. Components of visual orienting. In: Bouma H, Bouwhuis D, editors. Attention and performance. England: Erlbaum; 1984.

[54] Chica AB, Taylor TL, Lupiáñez J, Klein RM. Two mechanisms underlying inhibition of return. Exp Brain Res 2010;201:25-35. doi:10.1007/s00221-009-2004-1.

[55] Ratcliff R. Methods for dealing with reaction time outliers. Psychol Bull 1993;114:510-32. doi:10.1037/0033-2909.114.3.510.

[56] Team J. JASP (Version 0.9.1.0) [Computer software]. 2018.

[57] Beck AT. Cognitive therapy and the emotional disorders. Oxford, UK: International Universities Press; 1976.

[58] De Raedt R, Koster EHW. Understanding vulnerability for depression from a cognitive neuroscience perspective: A reappraisal of attentional factors and a new conceptual framework. Cogn Affect Behav Neurosci 2010;10:50-70. doi:10.3758/CABN.10.1.50.

[59] Chica AB, Martín-arévalo E, Botta F, Lupiá J. The Spatial Orienting paradigm : How to design and interpret spatial attention experiments. Neurosci Biobehav Rev 2014;40:35-51. doi:10.1016/j.neubiorev.2014.01.002.

[60] Kraft B, Jonassen R, Heeren A, Harmer C, Stiles T, Landrø NI. Attention Bias Modification in Remitted Depression Is Associated With Increased Interest and Leads to Reduced Adverse Impact of Anxiety Symptoms and Negative Cognition. Clin Psychol Sci 2019;7:530-44. doi: $10.1177 / 2167702618822480$.

[61] Hsu KJ, Mullarkey M, Dobias M, Beevers; CG, Björgvinsson T. Symptom-level network analysis distinguishes the unique associations of repetitive negative thinking and experiential avoidance on depression and anxiety in a transdiagnostic clinical sample 2019:Manuscr. Submitt. Publ. doi:10.31234/osf.io/z7fps.

[62] Clarke PJF, MacLeod C, Guastella AJ. Assessing the role of spatial engagement and disengagement of attention in anxiety-linked attentional bias: a critique of current paradigms and suggestions for future research directions. Anxiety, Stress Coping 2013;26:1-19. doi:10.1080/10615806.2011.638054.

[63] Grafton B, Macleod C. Engaging with the wrong people: The basis of selective attention to negative faces in social anxiety. Clin Psychol Sci 2016;4:793-804. doi:10.1177/2167702615616344.

[64] McNally RJ. Attentional bias for threat: Crisis or opportunity? Clin Psychol Rev 2019;69:4-13. doi:10.1016/j.cpr.2018.05.005.

[65] Rodebaugh TL, Scullin RB, Langer JK, Dixon DJ, Huppert JD, Bernstein A, et al. Unreliability as a Threat to Understanding Psychopathology: The Cautionary Tale of Attentional Bias. J Abnorm Psychol 2016;125:840-51. doi:10.1037/abn0000184.

[66] Waechter S, Nelson AL, Wright C, Hyatt A, Oakman J. Measuring Attentional Bias to Threat: Reliability of Dot Probe and Eye Movement Indices. Cognit Ther Res 2014;38:313-33. doi:10.1007/s10608-013-9588-2.

[67] Hedge C, Powell G, Sumner P. The reliability paradox: Why robust cognitive tasks do not produce reliable individual differences. Behav Res Methods 2018;50:1166-86. doi:10.3758/s13428-017-0935-1.

[68] Trafimow D. A defense against the alleged unreliability of difference scores. Cogent Math 2015;2:1-11. doi:10.1080/23311835.2015.1064626. 
[69] Bourgeois A., Chelazzi L., Vuilleumier P. How motivation and reward learning modulate selective attention. Prog Brain Res 2016:1-18. doi:10.1016/bs.pbr.2016.06.004.

[70] Browning M, Holmes E a., Harmer CJ. The modification of attentional bias to emotional information: A review of the techniques, mechanisms, and relevance to emotional disorders. Cogn Affect Behav Neurosci 2010;10:8-20. doi:10.3758/CABN.10.1.8.

[71] Fu CHY, Williams SCR, Cleare AJ, Brammer MJ, Walsh ND, Kim J, et al. Attenuation of the neural response to sad faces in major depression by antidepressant treatment: A prospective, event-related functional magnetic resonance imaging study. Arch Gen Psychiatry 2004;61:87789. doi:10.1001/archpsyc.61.9.877. 
Table 1

Details of exogenous cueing task studies with depressed or dysphoric groups

\begin{tabular}{|c|c|c|c|c|c|c|}
\hline Reference & $E C T$ & $\begin{array}{c}\text { Sample } \\
\text { size }\end{array}$ & Participants & Materials & Significant results and effect sizes & Conclusion \\
\hline [16] & $\begin{array}{l}300 \text { trials } \\
(+20 \text { catch } \\
\text { trials }) \\
\text { Non-predictive } \\
\text { cues } \\
\text { Discrimination } \\
\text { task } \\
\text { Fixation cues } \\
\text { SOA: } 1500 \mathrm{~ms} \\
(+50 \mathrm{~ms} \text { mask })\end{array}$ & 94 & $\begin{array}{l}\text { Undergraduate students (non- } \\
\text { patients), mostly women with self- } \\
\text { reported depression } \\
\text { Mean age: } 20 \text { years } \\
\text { (1) Moderate to severe symptoms } \\
\text { (BDI-II score between } 20 \text { and } 63 \text { ) } \\
\text { (2) Mild symptoms (BDI-II score } \\
\text { between } 14 \text { and } 19) \\
\text { (3) Healthy control (BDI-II < 14) }\end{array}$ & $\begin{array}{l}\text { Words } \\
50 \mathrm{sad}, 50 \text { positive, } \\
50 \text { neutral adjectives }\end{array}$ & $\begin{array}{l}\text { In group }(1): \mathrm{CV}_{\text {sad }}>\mathrm{CV}_{\text {neutral }} \\
{[t(32)=3.73, p<.001]} \\
\text { For } \mathrm{CV}_{\text {sad: }} \text { Group }(1)>\text { Group (3) } \\
{[F(1,92)=6.72, p<.05]} \\
\text { Effect sizes and standard deviations of } \\
C V \text { scores were not reported in the } \\
\text { paper. }\end{array}$ & $\begin{array}{l}\text { "Subclinically depressed individuals showed } \\
\text { maintained attention for negative words but only } \\
\text { in the moderate to severe depressive symptoms } \\
\text { group and not in the mild symptoms group." } \\
\text { "No bias was found for positive words" } \\
\text { (p. 1050). }\end{array}$ \\
\hline [14] & $\begin{array}{l}256 \text { trials }(+20 \\
\text { digit trials }) \\
\text { Non-predictive } \\
\text { cues } \\
\text { Detection task } \\
\text { Fixation cues } \\
\text { SOA: } 500 \mathrm{~ms} \\
\text { and } 1250 \mathrm{~ms}\end{array}$ & 883 & $\begin{array}{l}\text { Adult patients and non-patients } \\
\text { with diagnosis based on CIDI } \\
\text { Mean age: } 43 \text { years } \\
\text { (1) MDD (without dysthymia and } \\
\text { current or past anxiety disorder) } \\
\text { (2) MDD + anxiety disorder } \\
\text { (without dysthymia) } \\
\text { (3) History of MDD, no current } \\
\text { MDD or dysthymia or history of } \\
\text { anxiety disorder } \\
\text { (4) Comparison (no history of } \\
\text { depression or anxiety disorder) }\end{array}$ & $\begin{array}{l}\text { Words } \\
16 \text { threatening } \\
\text { words, } 16 \text { neutral } \\
\text { words, } 16 \text { negative } \\
\text { adjectives and } 16 \\
\text { positive adjectives } \\
\text { (from trait self- } \\
\text { descriptors of } \\
\text { depressive and manic } \\
\text { persons) }\end{array}$ & $\begin{array}{l}\text { In } 1250 \text { ms condition: } \\
\text { AB score }{ }_{\text {negative: }} \text { group }(3)>\text { Group (4) } \\
{[\text { mean difference }=9.07 \mathrm{~ms}, p=.04} \\
95 \% \text { CI }[0.20,17.93], d=0.20)]\end{array}$ & $\begin{array}{l}\text { "There was no evidence for a difference in } \mathrm{AB} \\
\text { towards negative adjectives or away from } \\
\text { positive adjectives in strictly defined clinical } \\
\text { groups of MDD participants with or without a } \\
\text { comorbid AD; (ii) specifically for longer duration } \\
\text { trials ( } 1250 \mathrm{~ms}) \text { " (p. 16). } \\
\text { "The rMDD group showed reduced inhibition of } \\
\text { return for negative adjectives than the } \\
\text { comparison group as reflected in higher } \\
\text { traditional AB scores than the comparison group } \\
\text { (...) this AB may reflect a heightened sensitivity } \\
\text { for negative adjectives" (p. 17). }\end{array}$ \\
\hline
\end{tabular}

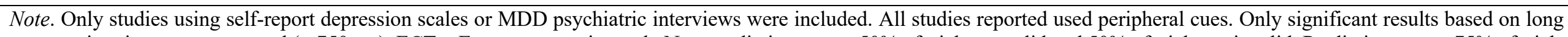

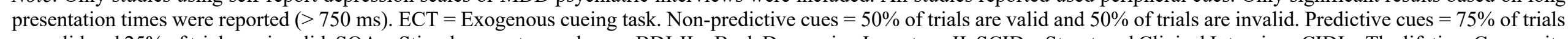

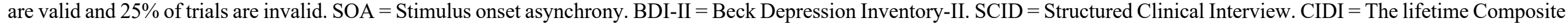

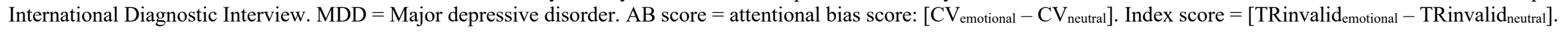


(continued)

\begin{tabular}{|c|c|c|c|c|c|c|}
\hline Reference & $E C T$ & $\begin{array}{c}\text { Sample } \\
\text { size }\end{array}$ & Participants & Materials & Significant results and effect sizes & Conclusion \\
\hline$[15]$ & $\begin{array}{l}360 \text { trials }(+72 \\
\text { catch trials }) \\
\text { Predictive cues } \\
\text { Detection task } \\
\text { Fixation cues } \\
\text { SOA: } \quad 17 \mathrm{~ms} \\
\text { and } 750 \mathrm{~ms}\end{array}$ & 118 & $\begin{array}{l}\text { Adult non-patients with diagnosis } \\
\text { based on the SCID with mood } \\
\text { induction conditions } \\
\text { Mean age: } 24 \text { years } \\
\text { (1) MDD (anxiety not excluded) } \\
\text { (2) Anxiety disorder (MDD not } \\
\text { excluded) } \\
\text { (3) Control: no psychopathology }\end{array}$ & $\begin{array}{l}\text { Scenes } \\
15 \text { threatening, } 15 \\
\text { sad, } 15 \text { neutral }\end{array}$ & $\begin{array}{l}\text { In } 750 \mathrm{~ms} \text { condition and neutral mood } \\
\text { induction condition: } \\
\text { Index score } \text { sad: }_{\text {Group }}(1)>\text { Group } \\
(3) \mathrm{n}\left[F(1,37)=5.2, p=.025, \eta_{\mathrm{p}}{ }^{2}=.12\right]\end{array}$ & $\begin{array}{l}\text { "Depressed participants were slower to disengage } \\
\text { from supraliminal dysphoric pictures than neutral } \\
\text { pictures during the neutral condition" (p. 132). }\end{array}$ \\
\hline $\begin{array}{l}{[17]} \\
\text { Part I }\end{array}$ & $\begin{array}{l}120 \text { trials }(+20 \\
\text { digit trials }) \\
\text { Non-predictive } \\
\text { cues } \\
\text { Detection task } \\
\text { Fixation cues } \\
\text { SOA: } 1500 \mathrm{~ms} \\
(+50 \mathrm{~ms} \text { mask })\end{array}$ & 30 & $\begin{array}{l}\text { Undergraduate students (non- } \\
\text { patients) with self-reported } \\
\text { depression } \\
\text { Mean age: } 19 \text { years } \\
\text { (1) Dysphoric ( }>9 \text { BDI-II) } \\
\text { (2) Nondysphoric }(<5 \text { BDI-II) }\end{array}$ & $\begin{array}{l}\text { Words } \\
5 \text { sad, } 5 \text { positive self- } \\
\text { referring adjectives } \\
\text { and } 5 \text { neutral nouns }\end{array}$ & $\begin{array}{l}\text { In group (1): } \mathrm{CV}_{\text {sad }}>\mathrm{CV}_{\text {neutral }} \\
{\left[t(14)=2.26, p<.05, \eta_{\mathrm{p}}^{2}=.27\right]} \\
\text { In group (2): } \mathrm{CV}_{\text {sad }}>\mathrm{CV}_{\text {neutral }}[t(14)= \\
\left.2.05, p<.05, \eta_{\mathrm{p}}^{2}=.15\right] \\
\text { In group (2): } \mathrm{CV}_{\text {positive }}>\mathrm{CV}_{\text {neutral }}[t(14)= \\
\left.2.21, p<.05, \eta_{\mathrm{p}}^{2}=.26\right]\end{array}$ & $\begin{array}{l}\text { "The results suggest that dysphoria is associated } \\
\text { with maintained attention for negative words (...). } \\
\text { However, the cue validity effect for negative } \\
\text { words failed to differ significantly between the } \\
\text { dysphoric group and the control group." } \\
\text { "In the nondysphoric individuals, an enhanced } \\
\text { cue validity effect (...) were found for both } \\
\text { negative and positive words. This indicates that } \\
\text { the nondysphoric individuals maintained attention } \\
\text { to emotional material in general" (p. } 449) \text {. }\end{array}$ \\
\hline Part II & $\begin{array}{l}190 \text { trials } \\
\text { Non-predictive } \\
\text { cues } \\
\text { Detection task } \\
\text { Fixation cues } \\
\text { SOA: } 250,500 \\
\text { and } 1500 \mathrm{~ms}\end{array}$ & 40 & $\begin{array}{l}\text { Non-patients: women with self- } \\
\text { reported depression } \\
\text { Mean age: } 22 \text { years } \\
\text { (1) Dysphoric ( }>9 \text { BDI-II) } \\
\text { (2) Nondysphoric ( }<5 \text { BDI-II) }\end{array}$ & $\begin{array}{l}\text { Words } \\
15 \text { sad, } 15 \text { positive } \\
\text { self-referring } \\
\text { adjectives and } 15 \\
\text { neutral nouns }\end{array}$ & $\begin{array}{l}\underline{\text { In } 1500 \mathrm{~ms} \text { condition }} \\
\text { In group (1): } \mathrm{CV}_{\text {sad }}>\mathrm{CV}_{\text {neutral }} \\
{\left[t(18)=2.38, p<.05, \eta_{\mathrm{p}}{ }^{2}=.24\right]} \\
\text { In group (2): } \mathrm{CV}_{\text {positive }}>\mathrm{CV}_{\text {neutral }}[t(19)= \\
\left.1.90, p=.07, \eta_{\mathrm{p}}^{2}=.15\right] \\
\left.\text { For } \mathrm{CV} \text { sad: Group }(1)>\mathrm{Group}_{\text {(2) }}\right) \\
{\left[t(38)=2.41, p<.05, \eta_{\mathrm{p}}{ }^{2}=.13\right]}\end{array}$ & $\begin{array}{l}\text { "Evidence was found for an attentional bias to } \\
\text { negative information in dysphoric persons. They } \\
\text { had an enhanced cue validity effect for negative } \\
\text { word (...) at } 1,500 \mathrm{~ms} \text { " } \\
\text { "Nondysphoric individuals attended to positive } \\
\text { words whereas dysphoric individuals did not." } \\
\text { (pp. } 451-452) \text {. }\end{array}$ \\
\hline
\end{tabular}

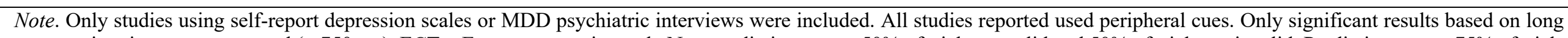

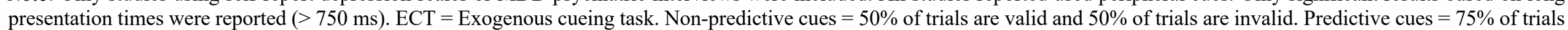

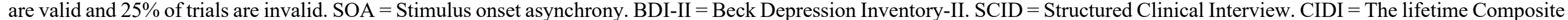

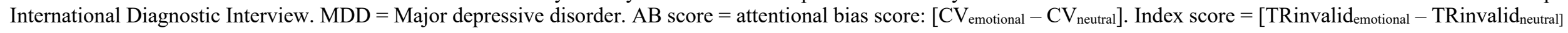


Table 2

Group characteristics

Group

Measure

Clinically

Subclinically

Never-

depressed

depressed

depressed

$\mathrm{N}$

34

35

26

Age

$40.74(10.22)$

$36.17(10.65)$

$36.92(12.51)$

Gender ratio (M/F)

$14 / 20$

$11 / 24$

$8 / 18$

Employment status

Student

3

Worker

8

Employee

13

Executive

Independent

Homemaker

Unemployed

Retired

2

1

3

3

1

Have children

24

18

14

Unable to work

20

6

0

With history of depression

23

14

0

Currently on psychotropic medication

18

4

0

(antidepressant)

SSRI

10

SNRI

2

NDRI

Tricyclic

Missing

1

2

3

Currently on psychotropic medication (anxiolytic)

5

25

5

0

Have comorbid dysthymia

14

1

0

Have trauma in last six months

8

7

0

0

0

0

0

Note. Standard deviations are shown in parentheses. SSRI = Selective Serotonin Reuptake Inhibitor. SNRI = Selective Norepinephrine Reuptake Inhibitors. NDRI = Norepinephrine-Dopamine Reuptake Inhibitor. 
Table 3

Means and standard deviations for all scales

\section{Group}

\begin{tabular}{|c|c|c|c|c|c|c|}
\hline \multirow[t]{2}{*}{ Measure } & \multicolumn{2}{|c|}{$\begin{array}{l}\text { Clinically } \\
\text { depressed }\end{array}$} & \multicolumn{2}{|c|}{$\begin{array}{c}\text { Subclinically } \\
\text { depressed }\end{array}$} & \multicolumn{2}{|c|}{ Never-depressed } \\
\hline & Mean & $S D$ & Mean & $S D$ & Mean & $S D$ \\
\hline BDI-II*** & 28.47 & 11.06 & 16.34 & 5.23 & 2.85 & 2.44 \\
\hline STAI-T*** & 56.35 & 9.72 & 47.83 & 7.45 & 32.31 & 8.21 \\
\hline STAI-S*** & 46.82 & 11.61 & 32.63 & 7.2 & 26.77 & 6.00 \\
\hline RRS - Brooding*** & 13.76 & 3.04 & 11.77 & 3.48 & 8.77 & 3.1 \\
\hline TEPS - Anticipatory pleasure** & 34.64 & 9.46 & 43.77 & 6.94 & 44.62 & 6.77 \\
\hline TEPS - Consummatory pleasure** & 29.56 & 7.85 & 36.66 & 5.96 & 36.65 & 6.42 \\
\hline $\begin{array}{l}\text { Note. BDI-II = Beck Depression Inven } \\
\text { State version of the State-Trait Anxiety } \\
\text { TEPS }- \text { Anticipatory pleasure }=\text { Tem } \\
\text { consummatory pleasure }=\text { Temporal Ex } \\
* * * p<.05 \text { Significant differences betw } \\
* * p<.05 \text { Significant differences betw } \\
\text { depressed groups. }\end{array}$ & $\begin{array}{l}\text {-II. STA } \\
\text { entory. } \\
\text { l Exper } \\
\text { ence of } \mathrm{I} \\
\text { all three } \\
\text { two gro }\end{array}$ & $\begin{array}{l}\text { Trait } \\
- \text { Broo } \\
\text { of Ple } \\
\text { ure Scal } \\
\text { ps } \\
\text { out no }\end{array}$ & $\begin{array}{l}\text { n of the } \\
=\text { Rumil } \\
\text { Scale, } \\
\text { nsumm: } \\
\text { nces be }\end{array}$ & $\begin{array}{l}\text {-Trait } \\
\text { Resp }\end{array}$ & $\begin{array}{l}\text { ety Inver } \\
\text { scale, bro } \\
\text { easure su } \\
\text { scale. } \\
\text { lly depre }\end{array}$ & $\begin{array}{l}\text { STAI } \\
\text { subs } \\
\text { e. TEI }\end{array}$ \\
\hline
\end{tabular}


Table 4

Mean reaction times in milliseconds, standard deviations, and mean cue validity (CV) as a function of group, validity, cue valence and materials

\begin{tabular}{|c|c|c|c|c|c|c|c|c|c|c|c|}
\hline \multirow[b]{4}{*}{ Material } & \multicolumn{11}{|c|}{ Group } \\
\hline & \multirow[b]{3}{*}{$\begin{array}{c}\text { Cue } \\
\text { valence }\end{array}$} & \multirow[b]{3}{*}{ Validity } & \multirow{2}{*}{\multicolumn{3}{|c|}{ Clinically depressed }} & \multirow{2}{*}{\multicolumn{3}{|c|}{$\begin{array}{c}\text { Subclinically } \\
\text { depressed }\end{array}$}} & \multirow{2}{*}{\multicolumn{3}{|c|}{ Never-depressed }} \\
\hline & & & & & & & & & & & \\
\hline & & & Mean & $S D$ & $C V$ & Mean & $S D$ & $C V$ & Mean & $S D$ & $C V$ \\
\hline \multirow[t]{6}{*}{ Scenes } & Neutral & Invalid & 567 & 144 & 24 & 526 & 176 & 22 & 517 & 116 & 3 \\
\hline & & Valid & 543 & 129 & & 504 & 151 & & 514 & 135 & \\
\hline & Happy & Invalid & 584 & 156 & 41 & 520 & 158 & 16 & 525 & 152 & 14 \\
\hline & & Valid & 543 & 134 & & 504 & 153 & & 511 & 143 & \\
\hline & $\mathrm{Sad}$ & Invalid & 573 & 130 & 28 & 518 & 154 & 16 & 520 & 135 & -6 \\
\hline & & Valid & 545 & 132 & & 502 & 145 & & 526 & 147 & \\
\hline \multirow[t]{6}{*}{ Faces } & Neutral & Invalid & 568 & 148 & 41 & 542 & 141 & 32 & 497 & 111 & 23 \\
\hline & & Valid & 527 & 145 & & 510 & 143 & & 474 & 96 & \\
\hline & Happy & Invalid & 564 & 154 & 44 & 557 & 159 & 54 & 492 & 98 & 13 \\
\hline & & Valid & 520 & 147 & & 503 & 144 & & 479 & 101 & \\
\hline & $\mathrm{Sad}$ & Invalid & 559 & 135 & 34 & 541 & 148 & 34 & 489 & 101 & 10 \\
\hline & & Valid & 525 & 147 & & 507 & 135 & & 479 & 101 & \\
\hline \multirow[t]{6}{*}{ Words } & Neutral & Invalid & 555 & 113 & 29 & 525 & 123 & 14 & 525 & 127 & 3 \\
\hline & & Valid & 526 & 126 & & 511 & 147 & & 522 & 123 & \\
\hline & Happy & Invalid & 557 & 126 & 32 & 518 & 126 & 23 & 533 & 134 & 14 \\
\hline & & Valid & 525 & 124 & & 495 & 132 & & 519 & 120 & \\
\hline & $\mathrm{Sad}$ & Invalid & 553 & 130 & 25 & 523 & 134 & 9 & 548 & 154 & 35 \\
\hline & & Valid & 528 & 124 & & 514 & 147 & & 513 & 110 & \\
\hline
\end{tabular}


Table 5

F-tests, p-values and effect sizes as a function of material and mixed-design ANOVA

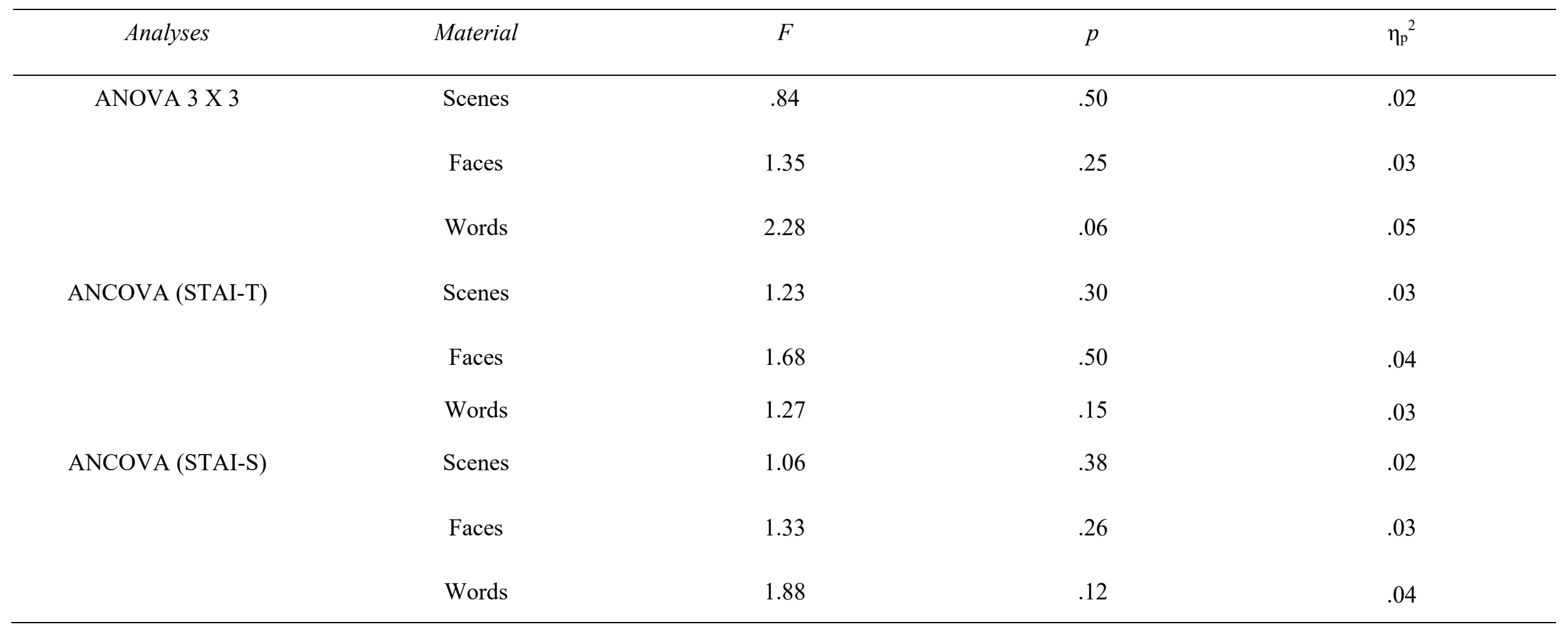

Note. ANOVA 3 X 3 = 3 (Valence: sad, happy and neutral) X 3 (Group: clinically depressed, subclinically depressed, never-depressed) mixed-design analysis of variance on CV scores. ANCOVA (STAI-T) $=3$ (Valence: sad, happy and neutral) X 3 (Group: clinically depressed, subclinically depressed, never-depressed) mixed-design analysis of covariance on CV scores with trait anxiety scores as a covariate. ANCOVA (STAI-S) $=3$ (Valence: sad, happy and neutral) X 3 (Group: clinically depressed, subclinically depressed, never-depressed) mixed-design analysis of covariance on $\mathrm{CV}$ scores with state anxiety scores as a covariate. 
Table 6

Independent sample t-tests for each group on CV scores

\begin{tabular}{|c|c|c|c|c|c|c|c|}
\hline Valence & Group contrast & Material & $\begin{array}{l}\text { CV Mean } \\
\text { difference }\end{array}$ & $p$ & $\begin{array}{l}\text { CI Lower } \\
\text { bound }\end{array}$ & $\begin{array}{l}\text { CI Upper } \\
\text { bound }\end{array}$ & $d$ \\
\hline \multirow[t]{6}{*}{ Sad } & Clinically depressed versus Never-depressed & Scenes & 34 & .02 & -12.42 & 13.72 & .65 \\
\hline & & Faces & 24 & .19 & -16.86 & 17.57 & .35 \\
\hline & & Words & 10 & .56 & -17.04 & 16.73 & .15 \\
\hline & Subclinically depressed versus Never-depressed & Scenes & 22 & .18 & -14.83 & 15.54 & .36 \\
\hline & & Faces & 24 & .18 & -16.02 & 16.74 & .36 \\
\hline & & Words & 26 & .13 & -16.89 & 16.58 & .15 \\
\hline \multirow[t]{6}{*}{ Happy } & Clinically depressed versus Never-depressed & Scenes & 27 & .15 & -17.56 & 18.33 & .38 \\
\hline & & Faces & 31 & .05 & -14.37 & 15.42 & .53 \\
\hline & & Words & 18 & .26 & -14.77 & 15.37 & .30 \\
\hline & Subclinically depressed versus Never-depressed & Scenes & 2 & .94 & -16.68 & 16.72 & .02 \\
\hline & & Faces & 41 & .02 & -15.38 & 16.66 & .64 \\
\hline & & Words & 9 & .55 & -13.76 & 14.08 & .16 \\
\hline
\end{tabular}

Note. $C I=95 \%$ confidence interval. $d=$ Cohen's $d$ score. 
Table 7

Paired sample t-tests for each valence on CV scores

\begin{tabular}{|c|c|c|c|c|c|c|c|}
\hline Group & Valence contrast & Material & $\begin{array}{l}\text { CV Mean } \\
\text { difference }\end{array}$ & $p$ & $\begin{array}{l}\text { CI Lower } \\
\text { bound }\end{array}$ & $\begin{array}{c}\text { CI Upper } \\
\text { bound }\end{array}$ & $d$ \\
\hline \multirow[t]{3}{*}{ Clinically depressed } & Sad versus Neutral & Scenes & 4 & .37 & -10.72 & 10.57 & .08 \\
\hline & & Faces & 7 & .68 & -15.20 & 15.39 & .09 \\
\hline & & Words & 4 & .66 & -15.14 & 15.28 & .07 \\
\hline \multirow[t]{3}{*}{ Subclinically depressed } & Sad versus Neutral & Scenes & 6 & .78 & -15.10 & 15.30 & .10 \\
\hline & & Faces & 2 & .80 & -11.85 & 11.76 & .04 \\
\hline & & Words & 5 & .65 & -13.87 & 14.00 & .06 \\
\hline \multirow[t]{3}{*}{ Never-depressed } & Happy versus Neutral & Scenes & 11 & .42 & -16.54 & 16.16 & .19 \\
\hline & & Faces & 10 & .32 & -15.97 & 16.31 & .17 \\
\hline & & Words & 11 & .25 & -18.07 & 17.75 & .16 \\
\hline
\end{tabular}

Note. $C I=95 \%$ confidence interval. $d=$ Cohen's $d$ score. 
Fig. 1. Enrollment chart.

Selection

Enrollment

Completion

Analysis
Assessed for eligibility : Internet study

$\&$ institutions $(\mathrm{n}=535)$

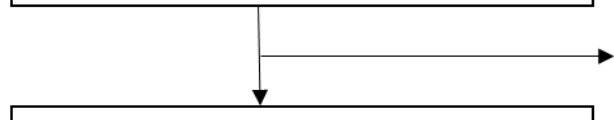

Contacted for further screening $(n=194)$

Completed the evaluation

$\mathrm{n}=112$

$\mathrm{n}=95$
Did not meet initial eligibility criteria $(n=341)$

No answer $(\mathrm{n}=40)$

Refused ( $\mathrm{n}=12)$

Psychotic disorder $(\mathrm{n}=1)$

History of substance abuse or dependence without at least 3 years of stabilization $(n=5)$

Neurological history $(n=7)$

Non-normal or corrected to normal vision $(n=2)$

Anxiolytic/drug consumption the same day $(\mathrm{n}=4)$

Recent change in antidepressant medication $(n=5)$

BDI scores $(n=6)$ 
Fig. 2. Stimulus presentation in a valid trial (e.g., faces).

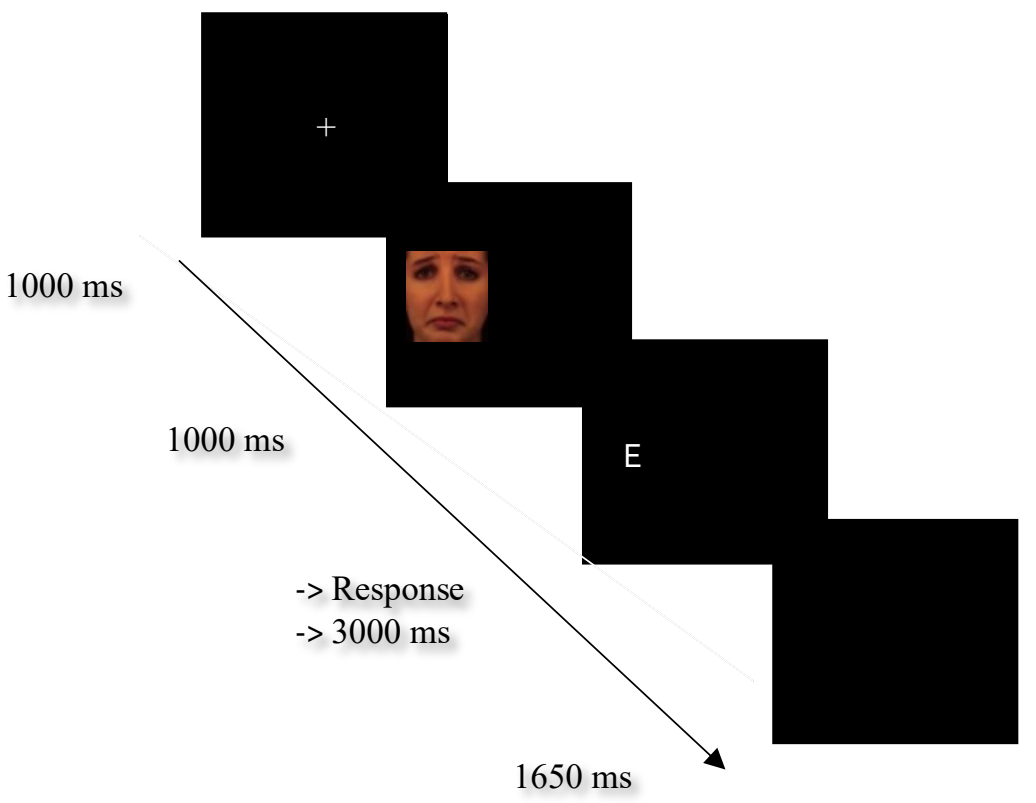

